\title{
Envisioning a future for Bornean orangutans: Conservation impacts of action plan implementation and recommendations for improved population outcomes
}

\author{
JULIE SHERMAN ${ }^{1, \vartheta}$, MARC ANCRENAZ ${ }^{2,3}$, MARIA VOIGT ${ }^{4,5}$, FELICITY ORAM $^{6}$, TRULY SANTIKA ${ }^{5,7}$, \\ SERGE WICH ${ }^{8}$, ERIK MEIJAARD ${ }^{2,5,7, \vee \varphi}$ \\ ${ }^{1}$ Wildlife Impact. PO Box 31062, Portland, OR 97217, USA. Tel./Fax.: +1503-5483013, `email: julie@ wildlifeimpact.org. \\ ${ }^{2}$ Borneo Futures. Block D, Unit 8, 1st Floor, Shakirin Complex,Spg 88, Kg Kiulap, BSB BE1518, Negara Brunei Darussalam. Tel./fax.: +31-615350744, \\ "email: emeijaard@gmail.com. \\ ${ }^{3}$ HUTAN-Kinabatangan Orangutan Conservation Programme. P.O. Box 17793, 88874 Kota Kinabalu, Sabah, Malaysia \\ ${ }^{4}$ German Centre for Integrative Biodiversity Research (iDiv), Halle-Jena-Leipzig, Deutscher Platz 5e, 04103 Leipzig, Germany \\ ${ }^{5}$ Durrell Institute of Conservation and Ecology, School of Anthropology and Conservation, University of Kent. Canterbury CT2 7NR, UK \\ ${ }^{6}$ PONGO Alliance. L-1-8 The Peak Suites, Jalan Signal Hill Park, 88400 Kota Kinabalu, Sabah, Malaysia \\ ${ }^{7}$ School of Biological Sciences, University of Queensland. QLD 4072, Australia \\ ${ }^{8}$ School of Natural Science and Psychology, Liverpool John Moores University. Tithebarn St Liverpool L2 2QP, UK
}

Manuscript received: 15 November 2019. Revision accepted: 8 January 2020.

\begin{abstract}
Sherman J, Ancrenaz M, Voigt M, Oram F, Santika T, Wich S, Meijaard E. 2020. Envisioning a future for Bornean orangutans: Conservation impacts of action plan implementation and recommendations for improved population outcomes. Biodiversitas 21: 465477. Populations of the Critically Endangered Bornean orangutan (Pongo pygmaeus) are declining despite more than 10 years of conservation action plan implementation. Here we analyzed the impacts on species' population and habitat from orangutan conservation strategies implemented between 2007 and 2017. We also assessed data on investments into orangutan conservation, orangutan population trends and landcover change in orangutan range between 2007 and 2017. Diverse strategies addressed the range of threats to orangutans but were not implemented at scales that impacted species' level populations and habitats. Since 2007 orangutan populations and forests across orangutan range have declined, with orangutan killing and deforestation as the major drivers of loss. Protected areas have increased since 2007, notably in Malaysian range states and in Central Kalimantan, Indonesia. However, $80 \%$ or tens of thousands of orangutans live outside protected areas in Kalimantan alone. Our results underscore scientific findings that have demonstrated this species' resiliency and modified previous understanding of their habitat use. Orangutans are regularly found using agriculture landscapes (acacia, oil palm, and timber plantations), and exploited forests. This plasticity must be considered to design more effective orangutan conservation strategies. We need to revise the notion of "orangutan habitat" to extend beyond forests alone, incorporating all landscapes where $P$. pygmaeus can be found. Orangutans cannot survive in exclusively monoculture production areas; they need some natural forest to fulfill their ecological requirements. However, individuals surviving in isolated forest patches or mosaic landscapes play an important role in sustaining the long-term viability of the local metapopulation through provision of crucial genetic, reproductive and socioecological connectivity. Our findings suggest removing these individuals through translocations weakens overall metapopulation health. All necessary efforts must be made to maintain individuals in isolated forest patches or mosaic landscapes in order to support healthy metapopulations. Improved orangutan population outcomes will require addressing habitat connectivity at the landscape level, incorporating both non-forested and anthropogenically modified areas, and developing efficient management strategies for human and orangutan co-existence within these multiple-use landscapes.
\end{abstract}

Keywords: Bornean orangutan, conservation, impact evaluation, Pongo pygmaeus

\section{INTRODUCTION}

The primary habitat for the Bornean orangutan is lowland mosaic and alluvial forests below 500m a.s.l. in Sarawak and Sabah, Malaysia, and Kalimantan, Indonesia (Wich et al. 2008; Husson et al. 2009). Orangutan distribution range is further limited by high mean annual rainfall, as this leads to soil leaching and decreased forest productivity (Wich et al. 2012). The range also reflects early settlement on Borneo (Santika et al. 2017), with subsequent likelihood of orangutan hunting (Davis et al. 2013). There are three subspecies of Pongo pygmaeus: $P$. p. wurmbii (mainly in Kalimantan, Indonesian Borneo), $P$. p. pygmaeus (mainly in Sarawak, Malaysia, and northern West Kalimantan), and P. p. morio (mainly in Sabah,
Malaysia, and North Kalimantan). Although all these three subspecies are fully protected under both Malaysian and Indonesian laws, they continue to be threatened by habitat loss, degradation and fragmentation due to conversion for agriculture, mining and infrastructure development (Gaveau et al. 2013; Santika et al. 2015), and by illegal hunting as bushmeat (Davis et al. 2013; Abram et al. 2015), which can, in turn, lead to wildlife trade of infants following killing of mothers, or retaliatory killing as a result of conflict with humans (Meijaard et al. 2011). Other threats include fire, climate change, or diseases (Ancrenaz et al. 2016). The Bornean orangutan (Pongo pygmaeus) was recently classified as Critically Endangered by the IUCN, and the populations of all subspecies are considered to be declining (Ancrenaz et al. 2016). 


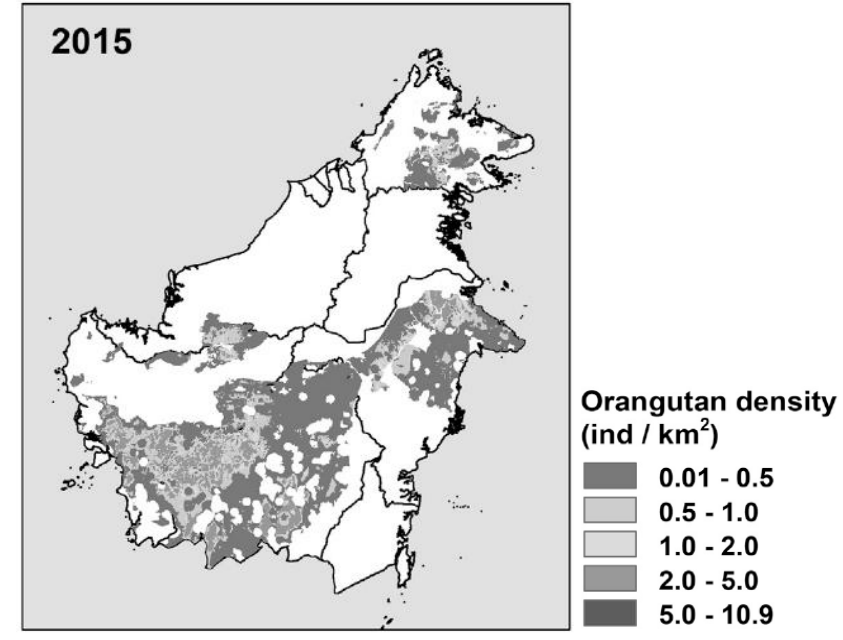

Figure 1. Map showing island of Borneo and the range and density variation of the Bornean orangutan in 2015. Figure from Voigt et al. (2018).

Management strategies for the Bornean orangutan have been outlined in three action plans, the Sabah Orangutan Action Plan (SAP), the Orangutan Indonesia Conservation Strategies and Action Plan (SRAK), and the Orangutan Strategic Action Plan for the Trans-boundary Biodiversity Conservation Area of Batang Ai, Lanjak-Entimau Wildlife Sanctuary and Betung Kerihun National Park (Transboundary Plan). The SAP was primarily developed via a series of consultation workshops led by the Sabah Wildlife Department (SWD) and HUTAN, and covered the years 2012-2016 (Sabah Wildlife Department 2012). The SRAK was developed following an Orangutan Population and Habitat Viability Assessment (PHVA) in 2005, and government and stakeholder planning workshops on conservation action strategies. The SRAK covered Sumatran and Bornean orangutan management for the years 2007-2017 (Ministry of Forestry 2009). A SRAK covering the years 2019-2029 was published in August 2019 but was later withdrawn for further revisions (Foresthints 2019). The Transboundary Plan was created by Wildlife Conservation Society (WCS) Malaysia and the Sarawak Forestry Corporation in cooperation with the International Tropical Timber Organization and Sarawak Forest Department. The plan covers the areas of Sarawak, Malaysia and Betung Kerihun National Park in West Kalimantan province, Indonesia for the period of 20102020 (Gumal and Braken Tisen 2010).

We conducted an independent evaluation of all these action plans, providing the first Borneo-wide appraisal of the implementation and impacts of conservation activities covering the entire Bornean orangutan range. We assessed available evidence on the impacts of implemented actions on Bornean orangutan populations and habitats between 2007 and 2017, and developed recommendations for strategic interventions going forward. Our aim is to disseminate findings to stakeholders including range state governments, non-governmental organizations, researchers, industry, and donors to inform and guide decision-makers on effective strategic actions for the protection of the Bornean orangutan across its range.

\section{MATERIALS AND METHODS}

\section{Study area \\ This study focused on Bornean orangutan range in Kalimantan, Indonesia and Sabah and Sarawak, Malaysia (Figure 1).}

\section{Procedures}

For this study, we compiled publicly available data on orangutan conservation interventions and impacts on orangutan populations and habitat between 2007 and 2017. We developed a conceptual model as a framework to investigate: (1) how the three orangutan action plans addressed the range of conservation interventions focused on orangutans; (2) what conservation impacts are expected from those interventions; and (3) what risks and opportunities are entailed by each intervention type.

Conservation interventions were broadly categorized as: (1) research; (2) habitat protection (legal designation, community land reserve, habitat purchase, land and fire management); (3) patrolling and law enforcement; (4) community outreach, training, and policy (awarenessraising, education, capacity building, policy development, and advocacy); (5) orangutan rescues, rehabilitation, reintroduction, and translocation; (6) habitat restoration; and (7) organization management, salaries, buildings, vehicles, and other administrative costs. We collected additional data on primary components of orangutan conservation action: (1) financial data on investments made into orangutan conservation for the latest available year (2016); (2) law enforcement data; (3) orangutan rescue and release data; (4) land cover change in orangutan range; and (5) orangutan population trends. Six categories of stakeholders conducted these activities: government; multilateral agencies (agencies representing multiple countries, such as the United Nations Environment Programme); corporate (timber, oil palm, pulp and paper companies, carbon trade, other); orangutan sanctuaries and rescue organizations; conservation non-governmental organizations (NGOs); and research organizations.

Data were gathered from direct communications with stakeholders (via phone, email and in-person interviews), review of published literature and unpublished data, and from publicly available data sources. These compiled data were used to assess progress first against the three action plans' self-determined measures of success (plan indicators), and secondly in terms of their implementation, outcomes, and impacts. Our aim was to seek potential improvement in the effectiveness of orangutan conservation activities, rather than to point out wrongdoing by any individual or group. Hence stakeholder inputs and publicly available data attributable to individual stakeholders were kept confidential and anonymous, with data collated by sector and strategy rather than by entity.

We undertook stakeholder outreach via a series of meetings, interviews, and consultations at the Orangutan 
Veterinary Advisory Group (Banda Aceh, July 2018), the Sabah Wildlife Department (SWD) (Kota Kinabalu, October 2018), and the West Kalimantan Balai Konservasi Sumber Daya Alam (BKSDA) (February 2019) and the SRAK national consultation process workshop (December 2017). We emailed questionnaires to 113 stakeholders representing government (agencies/entities emailed=12; respondents $=1$ ), industry (corporations emailed $=24$; respondents $=8$ ), research centers and universities (organizations emailed $=13$; respondents=4), zoos (organizations emailed $=17$; respondents $=4$ ), and NGOs (organizations emailed $=47$; respondents $=15$ ). Questions were designed to investigate: (1) respondents' awareness of the actions plans; (2) whether respondents used these plans to guide their activities; (3) the respondents' staff and yearly budget directed to orangutan conservation activities; (4) the impacts on orangutan conservation from respondents' orangutan-related activities; and (5) challenges faced. The project team held in-person or remote meetings/communications with an additional 47 stakeholders (orangutan socioecology, behavior, ecology or population researchers, $n=16$; great ape rescue and release or conservation researchers, $\mathrm{n}=3$; orangutan conservation practitioners, $\mathrm{n}=7$; government personnel, $\mathrm{n}=5$; representatives of eight orangutan rescue organizations, $\mathrm{n}=16$ ). Questionnaire recipients and other stakeholders were kept anonymous to maintain confidentiality.

We also collect data from newspaper articles by searching Prokal and TribunNews (Kalimantan), Jakarta Post (Indonesia), and Borneo Post, Star, Malay Mail, Daily Express, New Sarawak Tribune, and Borneo Today (Malaysia and Borneo regional) websites, using the search terms "orangutan" (Indonesian and Malaysian sources) and "orang-utan" (Malaysian sources) to capture any relevant news published between 2007 and 2018. Financial data were collated from annual reports and websites, email communications and direct interviews, while enforcement data were compiled from published sources, CITES reports, newspaper articles, government reports and NGO sources. Rescue and release data were collected from rescue centers' annual reports and tax filing or charity commission reports, direct communications with practitioners, and from websites and social media posts of NGO and government rescue centers holding Bornean orangutans in Kalimantan, Sabah and Sarawak. We provided initial datasets to each rescue center for their review and input in June 2017.

\section{Data analysis}

\section{Action plan implementation and stakeholder intervention} analyses

We reviewed available implementation data collected from stakeholder outreach, review of published and unpublished literature and publicly available sources, and coded every indicator for each action plan as: (0) not completed or unsuccessful in achieving indicator condition; (1) completed or successful in achieving indicator condition; (2) in progress; (3) unknown. For the Indonesian action plan we further cross-referenced the appropriateness of the indicators based on what they measured as follows:
(0) process or implementation progress; (1) indirect impact-creating enabling conditions for conservation (e.g., building capacity for law enforcement action or gazetting protection of orangutan habitat); (2) and direct impact on orangutan populations and habitat. We reviewed and summarized stakeholder questionnaire responses by respondent sector, prevalence of intervention types, reported results, and relation to relevant orangutan action plans.

We compiled data on annual captive populations and annual rescues and releases. We also compiled and coded available data on every individual instance of rescue and of release. We aggregated data by country and by rescue center or other entity and identified possible duplicates using any available combination of animal name, age, date, and circumstances of rescue. We excluded all duplicates and any records where it was unclear if the case had been previously recorded. We classified rescues as: (1) confiscation (seizure from owner); (2) surrender (willing handover by owner or rescuer); (3) wild capture (purposeful capture of wild orangutans, including for translocation to another habitat); (4) other rescue types (medical interventions or other rescues that are not seizures, surrenders or wild captures); and (5) re-captures of previously released orangutans. Releases were classified as: (1) reintroduction (release of ex-captive rehabilitated orangutans who spent more than six months in a captive facility); (2) wild-to-wild translocation ("translocation" per practitioner terminology; any wild orangutan captured and held six months or less); (3) wild captured orangutans held for more than six months in rescue center facilities; and (4) re-releases (release of previously released and recaptured orangutans).

We compiled publicly reported instances of infractions against orangutan protection laws and associated law enforcement. Data on illegal actions affecting orangutans included capture or possession of orangutans as pets, harassment, attacks or injury to orangutans, and orangutan killing. We excluded duplicate records of the same event and calculated the total number of incidents and the relative frequency of law enforcement actions of investigation, confiscation, arrest, and conviction.

\section{Financial analysis}

We analyzed data on 145 organizations' expenditures during 2016. The organizations include: government $(\mathrm{n}=$ 21); multi-lateral $(\mathrm{n}=4)$; corporate $(\mathrm{n}=59)$; sanctuaries/rescue centers $(n=12)$; NGOs $(n=23)$; and research organizations $(n=26)$. Data were actual figures published in the annual reports of government institutions, companies and NGOs, and estimates as to what percentage of the overall budgets were spent on different orangutan conservation strategies based on qualitative information in the annual reports, or data provided by the organizations' representatives in response to email requests for information. For oil palm concessions, we used 32 known Roundtable on Sustainable Palm Oil (RSPO)-certified concessions and their budget allocations to managing an estimated 275 orangutans in their estates and concessions (Meijaard et al. 2017). The choice to focus only on RSPO- 
certified concessions was based on the requirement for these companies to implement management that maintains orangutan populations in their concessions, and the independent audits of such management (RSPO 2018). For timber concessions, we used only those concessions certified by the Forest Stewardship Council (FSC), within $P$. pygmaeus range, because they would be regularly audited on the FSC requirement to prevent illegal hunting in their concessions (FSC 2009).

\section{Habitat changes, orangutan population trends and conservation considerations for metapopulations}

Last, we assessed recent orangutan population and habitat trends within state and province level geopolitical units of the orangutan range. Province (for Indonesia), state (for Malaysia) and country borders (for Brunei) were downloaded from the Global Administrative Areas database (GADM 2012), and combined within the extent of the island. Land use and management classes were assessed using a layer from Santika et al. (2017) of protected areas, selective timber extraction (hereafter selective logging) concessions in natural forest, industrial timber and industrial oil palm plantation concessions in 2006 and 2012. Suitable habitat was defined as pixels of all areas with orangutan densities higher than $0.01 \mathrm{ind} / \mathrm{km}^{2}$ (i.e. one orangutan per $100 \mathrm{~km}^{2}$ ) and that was forested (Santika et al. 2017; Voigt et al. 2018). All layers were resampled to a resolution of $1 \mathrm{~km}$, the highest resolution available for all layers, using nearest neighbor resampling for categorical and bilinear for continuous predictors. We extracted forest and suitable habitat extent, as well as orangutan numbers for the administrative units and land use classes on Borneo. To analyze the relative importance of small habitat patches within Bornean orangutan range, we also extracted the numbers of fragments smaller than 25 and $50 \mathrm{~km}^{2}$ in Sabah, Sarawak, and Kalimantan. All spatial calculations were done in Python, using numpy (Oliphant 2016), before being aggregated, analyzed and visualized in $\mathrm{R}$ ( $\mathrm{R}$ Core Development Team 2016) and ArcGIS (ESRI 2014). We reviewed published scientific literature, along with expert knowledge and unpublished results from orangutan research projects to investigate how population and habitat trends relate to current threats, orangutan habitat use and metapopulation functions, and conservation considerations.

\section{RESULTS AND DISCUSSION}

\section{Action plan implementation analyses}

Orangutan Conservation Action Plans covered most of the necessary actions to address the scope of threats to orangutan population and habitat. Our review found that $91 \%$ of the 164 indicators were measures of process or implementation effort and not effects of implemented actions (Figure 2). There was a strong focus on development of guidelines, Standard Operating Procedures (SOPs) and holding workshops, and dissemination of or access to these products. Only a few indicators measured direct impact to orangutan populations $(n=2)$, habitat $(n=4)$, or law enforcement $(n=1)$, or indirect impacts $(n=7)$. Both direct and indirect impact indicators lacked specifics such as number of hectares covered or percent of target areas addressed and thus were a count of activities rather than a measure of relative progress in habitat protection, reduction of threats, or behavior change in target stakeholder groups. For example, indicators include, "Revision to land use patterns that accommodate the habitat requirements of endangered species (esp. orangutans)", "Rehabilitation of 5 orangutan habitat areas", and "At least 1 area restored as an orangutan habitat". To measure impact, these indicators need to specify spatial extent and geographic information, otherwise, even one or a few instances mean the indicator is met without any relevance to the percentage of pertinent locations, relative amounts of orangutan habitat covered, and the salience of the particular location to orangutan population recovery or stabilization.

Although most actions described in the SRAK plan were underway, some of the most critical actions have been implemented only rarely, or not implemented at scales sufficient to influence species status and available habitat. Further, some actions were not based on best available science and understanding of orangutan behavior and habitat use (see results sections on Rescue and release, Law enforcement, Management of orangutans in concessions, and Changed thinking-what makes a habitat and what is an orangutan population?).

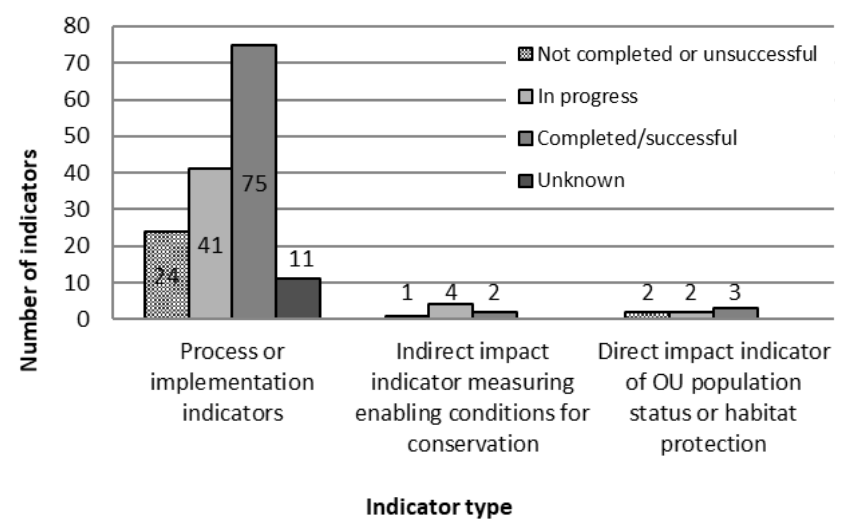

Figure 2. Progress on SRAK implementation by indicator type

Table 1. Summary of the different types of conservation activities that are the primary focus of the questionnaire respondents

\begin{tabular}{lc}
\hline Activity category & $\begin{array}{c}\text { Number of respondents } \\
\text { conducting strategy }\end{array}$ \\
\hline Orangutan research activities & 3 \\
Orangutan monitoring & 4 \\
Creation of protected areas & 3 \\
Habitat protection (include patrolling) & 7 \\
Conservation management capacity & 6 \\
and community outreach & 8 \\
Awareness & 4 \\
Land use planning & 7 \\
Reforestation and creation of corridors & 3 \\
Policy & \\
\hline
\end{tabular}


The Sabah Malaysia SAP called for the State to create a Sabah Orangutan Conservation Alliance (SOCA) to develop a feasible work plan and budget to implement the SAP. SOCA was not created during the study period, yet various organizations and partners undertook to deliver tangible results towards the completion of the plan. Most site-specific actions under the plan were completed during the study period, with the majority of non-site-specific actions being completed or in progress.

The Transboundary Plan indicators measure impacts on orangutan populations and habitats. Activities under the plan are monitored and measured against the plan indicators by the Sarawak Forestry Corporation (SFC), WCS Malaysia and other partners. Mid-terms successes have been documented including several high-profile arrests and subsequent prosecution (Pandong et al. 2019). The Transboundary Plan also details many activities to be undertaken by the Province of West Kalimantan to protect and manage $P$. pygmaeus. However, the Province authorities and their partners made very few references to this Transboundary Plan during the review and the revision of the Indonesian Action Plan.

The socialization of the three plans appears to be rather weak in all cases (see following section, Stakeholder interventions).

\section{Stakeholder interventions}

We received 32 responses from a stakeholder questionnaire sent to government, NGO and industry stakeholders. The most common stakeholder activities were awareness-raising, reforestation and forest protection (including patrols) (Table 1). Most stakeholders did not have or did not share empirical evidence of whether or how these activities were impacting orangutan populations and habitats. A total of 10 respondents (or 31\%) were aware of the Sabah State Action Plan; 15 of the Indonesian Action Plan (48\%); 3 of the Transnational Plan (10\%), and 7 $(22.5 \%)$ were not aware of any plan. Only one partner was aware of all three plans. Only four respondents were aware of how their activities might impact the status of orangutan populations or threats to these populations as a whole. Therefore it appears that most efforts are locally focused and do not address orangutan conservation issues at wider scales.

\section{Rescue and release}

We are conducting a full analysis of rescues and releases in Kalimantan between 2007 and 2017, and here report the trends shown in preliminary results. The Indonesia SRAK had a stated goal of emptying all rehabilitation centers by 2015 . In practice, rescue centers in Kalimantan have maintained fairly constant capacity, with more than 1000 orangutans held in their facilities in 2017, nearly the same number as held there in 2007. The pace of rescues continues to exceed that of releases despite more than 600 ex-captive orangutans having been released since 2007. Most rescues were orangutans held as pets or captured from areas where they could potentially interact with humans, principally agricultural concessions and local community lands. Interdiction of illegal trade played a minor role in orangutan rescues, with only a few rescued orangutans seized from traders. Consumption of human crops was specified or alluded to in only a small percentage of rescue records. A larger number of orangutans were affected by fires set to clear lands, which rescue centers report drive orangutans from forests into agricultural lands or villages where they could interact with humans.

We found more than 1200 detailed records on individual orangutans rescued, more than half of which represent crimes, including killing, possession, harassment/injury, sale or trade of orangutans. Nearly all orangutans surrendered (voluntarily handed over by a possessor), or confiscated by authorities were illegally held as pets. Nearly half of the total orangutans rescued were wild orangutans captured by orangutan management practitioners during the study period. Most of these wild orangutans were captured in situations where they were perceived to be at risk of potential interactions with humans, or where there was a perceived risk to human safety, food crops or property. Recorded orangutan consumption of human crops was specified in only a small percentage of the rescue records.

Of more than 1000 individual orangutans released into natural habitats between 2007 and 2017, 44\% were rehabilitated and reintroduced. More than half of these were adults 10 years or older that were captive for more than 10 years. Practitioners commonly reported that released animals had "behavioral issues" and "difficulties in adapting to social and ecological conditions" as well as conspecific conflicts, and, to a lesser degree, conflicts between rehabilitants and wild orangutans. Many rehabilitated orangutans were recaptured and released, sometimes repeatedly because they were malnourished to the point of starvation or due to reports of consumption of human crops or other interactions with humans or with other orangutans. Systematic post-release monitoring beyond three years (the typical maximum life span of radio-tracking implants) was rarely reported although some animals were recorded ad hoc by patrols or noted around feeding platforms on occasion. Many individuals were not seen again following release, regardless of monitoring schemes. Rescue centers tended to consider these unmonitored individuals to be alive but dispersed outside of monitoring range or with non-functioning tracking implants, but there was not clear evidence available to support this assumption. Some reports from long term release sites suggest that medium to long term survival rates for reintroduced orangutans may be lower than $20 \%$.

Between 2007 and 2017, wild orangutans were captured and moved in large numbers from concession lands slated to be cleared, and from areas that rescue centers considered marginal habitat or with high likelihood of humanorangutan interaction. Orangutans were mainly captured from the wild to pre-emptively avoid potential interactions with humans, including when people reported only seeing the orangutan or fearing it, but without any physical conflict or reported damage to property, such as crop consumption. Crop consumption and other orangutan damage to human property were specifically reported in one-fifth of the wild captures. The vast majority of wild orangutans were healthy at the time of capture. However, 
some were rescued from urgent situations where their welfare was under direct threat from humans attacking or harassing them, or when they were starving, dehydrated, or seriously injured. Rescues of the small minority of starving or malnourished animals were commonly associated with fires set to clear land. Approximately one-fifth of all the wild orangutans were captured when no suitable release site was available. These animals were held in captivity for several years before release.

Researchers we interviewed reported that mitigation or management of human-orangutan interactions is extremely rare, and translocations are the default answer to people wanting orangutans out of their way. There were multiple instances of these translocations being requested by corporations planning to clear land or to prevent orangutans in local forest patches from feeding in plantations. Anecdotal reports and available evidence of forest change in these areas suggest that following removal of the orangutans (the protected or "High Conservation Value" (HCV) species that cannot be moved or harmed under Indonesian conservation law UU 5 of 1990, and per certification requirements for sustainable timber and oil palm), these lands are rapidly cleared. While several wildto-wild translocation release sites have been extensively studied prior to their approval, stakeholders we communicated with reported that other release sites appear to be selected ad hoc without the necessary wild orangutan population surveys, food availability and other assessments needed to comply with IUCN Guidelines for Reintroduction (Beck et al. 2007; IUCN/SSC 2013). Few data are available on short term survival, and essentially none on long term survival of wild orangutans translocated to new habitats. Available short term survival data on a few radio-tracked translocated orangutans show two-thirds were not seen again after two years.

The state governments of Sabah and Sarawak, Malaysia, each operate rescue centers-Sepilok Orangutan Rehabilitation Centre (Sabah), and Semenggoh and Matang Wildlife Centers (Sarawak). Malaysian centers have rescued only a few orangutans annually during the study period. These rescues are almost exclusively infants. Both Sepilok and Matang release orangutans into the protected forests adjoining their rescue centers. Few publicly available data were found on these activities. However, it is highly likely success of reintroduction and translocation are limited in Malaysia by the same factors as in Indonesia.

\section{Law enforcement}

We are conducting a full analysis of orangutan-related crimes and law enforcement contexts, and here report trends from initial results. Systematic review of news articles and rescue data for this study showed that between 2007 and 2017 there were at least 946 incidents of orangutan-related crime in Kalimantan, Indonesia, and at least 50 incidents of orangutan-related crime in Sabah and Sarawak Malaysia. Few orangutan-related crimes perpetrated in Kalimantan were investigated, prosecuted or convicted during the study period. Indonesia did not make any convictions based solely on illegal orangutan possession between 2007 and 2017, although one person was convicted for local trade of a Bornean orangutan (Freund et al. 2017; Nijman 2017; Karokaro and Hanafiah 2019). Indonesia made six successful convictions of orangutan-related crime between 2007 and 2017, a conviction rate of less than $0.6 \%$ for all reported criminal activities during the study period. Malaysia made three successful convictions, a conviction rate of $6 \%$ for all orangutan-related crimes between 2007 and 2017.

\section{Management of orangutans in concessions}

Our stakeholder questionnaire data from eight concession companies and 15 NGOs indicate there is limited implementation of Best Management Practices (BMPs) at the local level in industrial concessions. Stakeholders reported that use of deterrents to keep orangutans out of crop areas in Kalimantan was uncommon, although we are aware of some instances of isolating an area with drains filled with water (since orangutans cannot swim). Stakeholders also reported concession managers do not plan operations in ways that would deter orangutans from crop-raiding.

\section{Financial analysis}

We analyzed the 2016 budgets of 145 organizations working on orangutan conservation, and allocated their funding within six broad orangutan conservation strategies (Figure 3). Most of the conservation investments were allocated in 2016 to rescues, rehabilitation, reintroduction, and translocation of orangutans (USD $\$ 5,365,873$ ), then community outreach, training and policy (USD $\$ 4,093,106$ ); habitat protection (USD \$3,941,563); law enforcement and patrolling (USD \$2,871,262); habitat restoration (USD \$2,835,977); and research (USD $\$ 2,235,782)$. The largest investor was the private sector, mainly concessions, (USD \$7,463,094), just ahead of the orangutan rescue centers (USD \$7,141,367). Government investment was fairly small comparatively, with approximately USD $\$ 1.7$ million focused on orangutan conservation implementation.

\section{Habitat loss and habitat protection}

Forests in orangutan range have declined since 2007. However, protected areas have increased, most notably within Sabah and Sarawak, Malaysia, and in Central Kalimantan. The Malaysian states of Sabah and Sarawak have decided to fully protect most of the orangutan range as a conservation strategy, and the recent surveys show the populations in these two states are becoming stable (Simon et al. 2019), except in non-protected or in fragmented forests. The network of fully protected forests in Kalimantan is smaller relative to forest extent and the prevalence of detected illegal activities (see Results sections on Rescue and release, and Law enforcement).

\section{Orangutan population trends}

Recent studies have strongly indicated that actual (not estimated) population size has dramatically decreased over the past 200 years (Goossens et al. 2006; Meijaard et al. 2010), and that this decline has continued over recent decades (Santika et al. 2017; Voigt et al. 2018). 
Contrary to these findings noted above, the Indonesian government has recently published monitoring data showing orangutan populations dramatically increasing, even in some cases more than doubling over a few years, a rate which is not biologically possible for orangutans (Meijaard et al. 2018; MOEF 2018). Some of the government monitoring data were from sites used for orangutan introductions or translocations (e.g., Bukit BakaBukit Raya National Park), implying that any net positive change in the monitored sites was inevitably preceded by at least an equally large negative change in non-monitored populations from which orangutans had been initially removed (KSDAE 2018). All the government monitoring sites are within protected areas, whereas the majority of orangutans occur in non-protected lands. It is thus scientifically unjustified to extrapolate population trends from these sampling sites to the total range of the species (Meijaard et al. 2018).

\section{Threats to the orangutan populations}

The loss of orangutans in primary and selectively logged forests between 1999 and 2015 accounted for between $67 \%$ and $83 \%$ of the total orangutan decline on Borneo, indicating that killing was an important driver of declines (Voigt et al. 2018). Deforestation and industrial oil palm and paper pulp plantations appeared to be responsible for about $9 \%$ of the total loss of orangutan abundance (Voigt et al. 2018). Nonetheless, it is apparent that the deforestation, plantation development and killing in conflict situations often go together as drivers of orangutan population declines (Santika et al. 2017).

\section{Changed thinking-what is orangutan habitat and what makes a population?}

Orangutan habitat is popularly described as intact native forest. However, wild orangutans have been increasingly found using forest fragments located in agricultural landscapes (Ancrenaz et al. 2015; Spehar and Rayadin 2017). Those fragmented forests and even the agricultural land used by orangutans are what make up their habitat (i.e. any area the animals use). Further, the full extent of this varied habitat should be considered part of the orangutan metapopulation habitat. Indeed, field observations show these small forest patches are used by resident female orangutans and visited by traveling males, demonstrating the role of these patches in providing connectivity within metapopulations (Ancrenaz et al. 2015). Removing and translocating animals found in these patches, and destroying these fragments, results in loss of connectivity and movement among elements of the orangutan metapopulation, posing risks to metapopulation viability (Figure 7).

\section{Value of forest fragments for orangutan conservation}

There are at least $6,620 \mathrm{~km}^{2}$ of forest fragments between 1 and $50 \mathrm{~km}^{2}$ in size across Borneo (Figure 8).

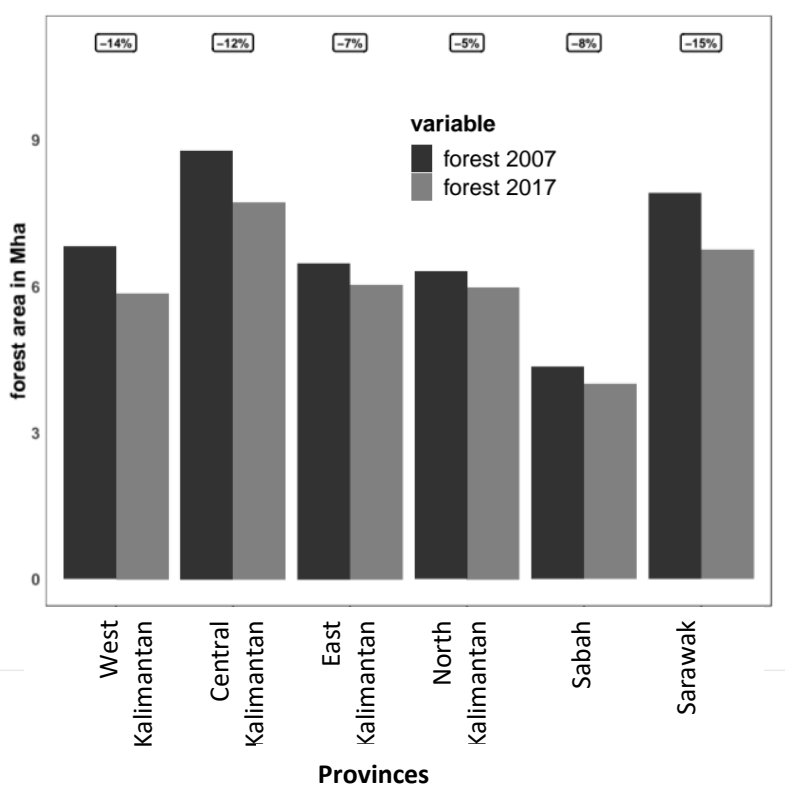

Figure 4. Forest change in Borneo by province between 2007 and 2017. Percent change is indicated in the rectangle. Forest cover is based on maps by (Gaveau et al. 2016)
Figure 3. Annual estimated budget allocations in 2016 to six different conservation strategies by six different types of organizations

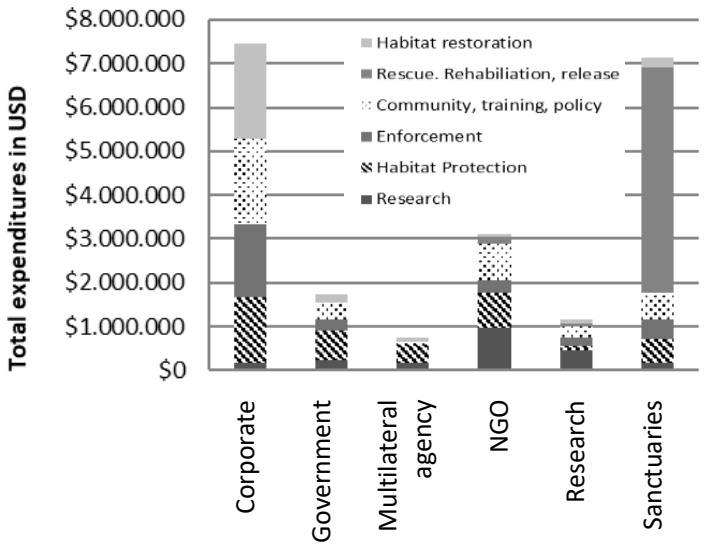

Sectors 


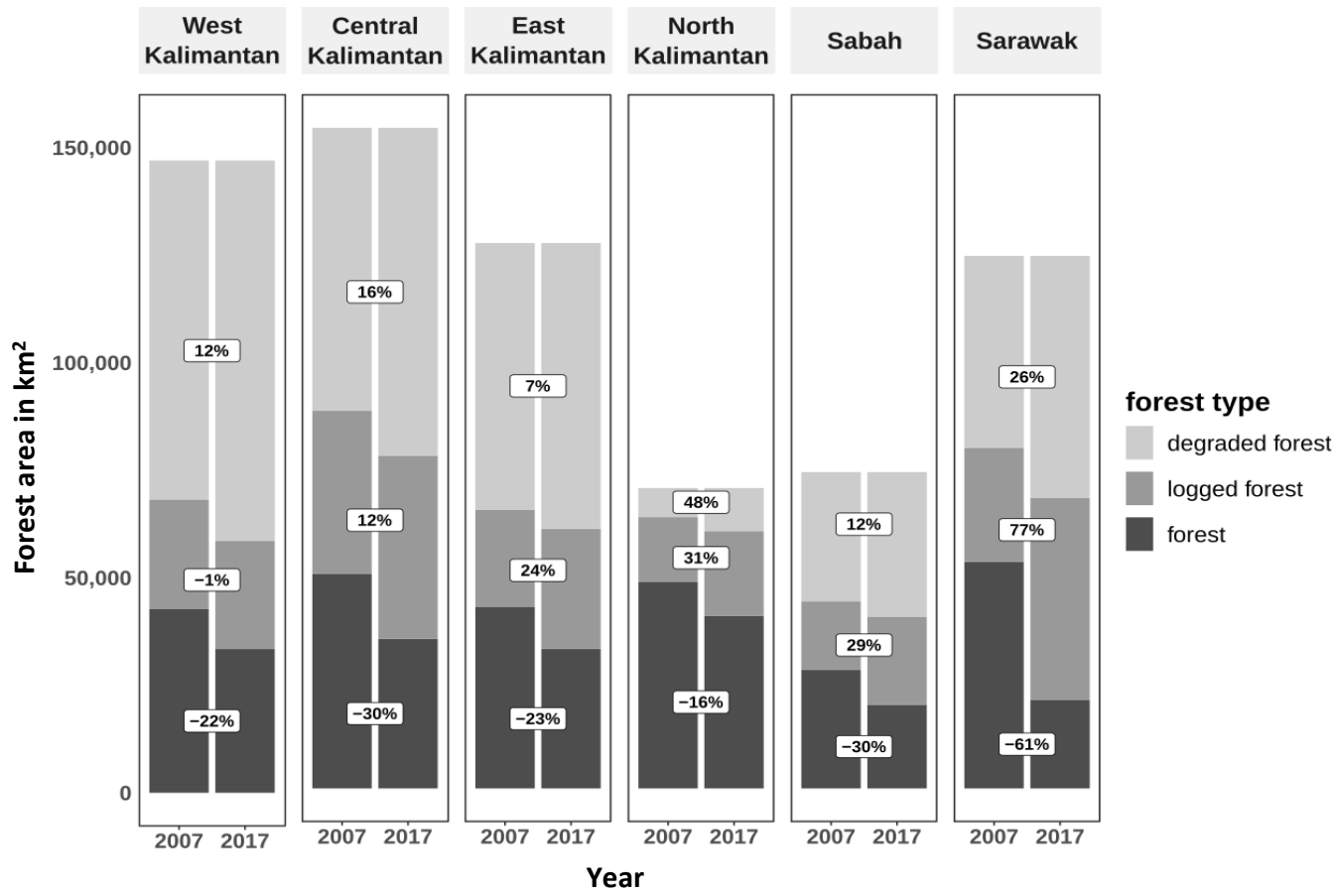

Figure 5. Forest change, degradation, and logging in Borneo by province, 2007-2017. Categories are: forest (unlogged, 100\% forest cover); logged (50-100\% forest cover); and degraded ( $>0-50 \%$ forest cover). Percent change is indicated in the rectangles. Forest cover is based on maps by Gaveau et al. (2016) and percent is derived from the percent 30x30m pixels within a 1x1 km pixel that were deforested

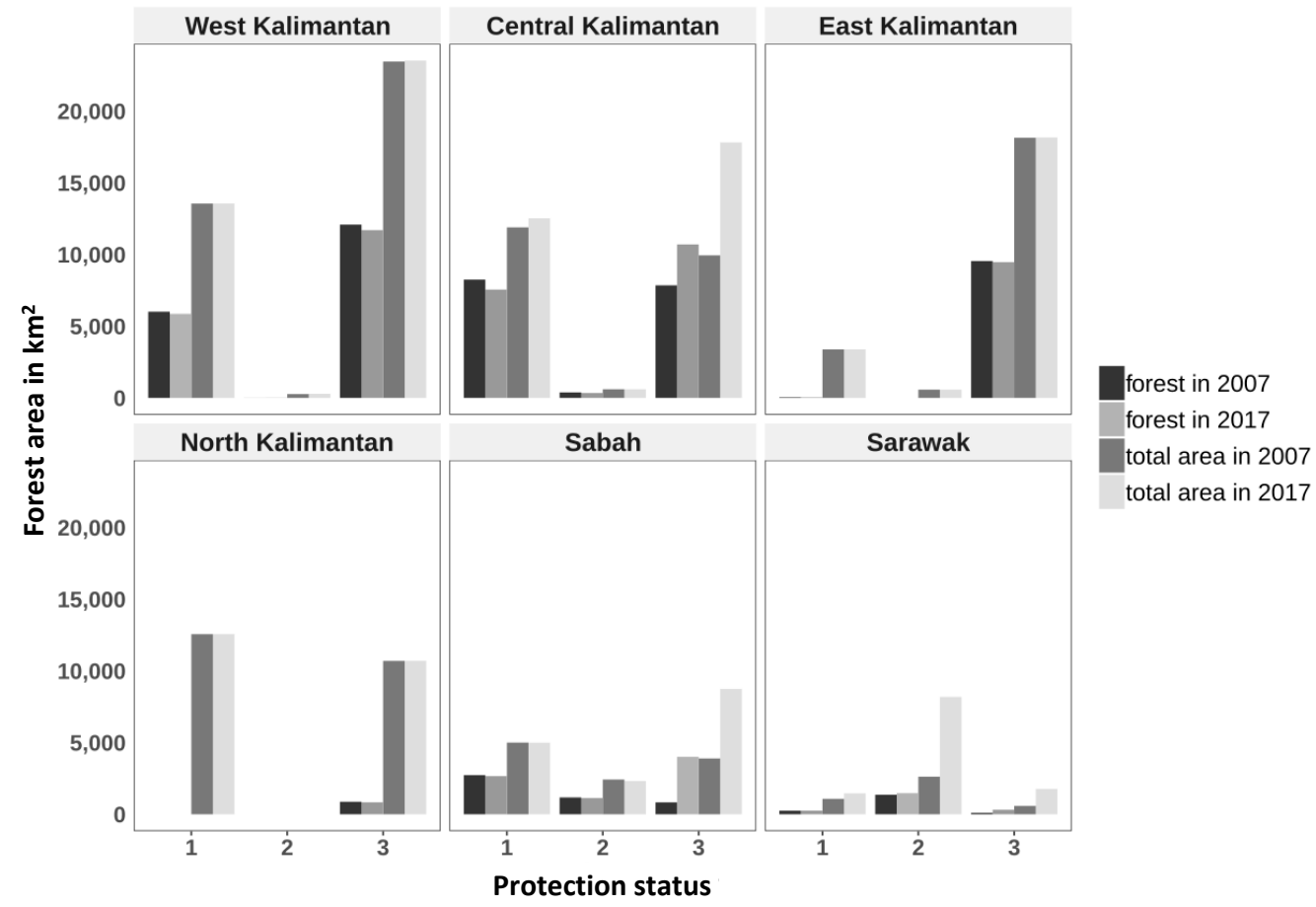

Figure 6. Change in forest area and total area under protection status by province, 2007-2017. Protection status 1 is IUCN category 1-3, status 2 is IUCN category 4-6, as well as "not reported" or "not applicable", status 3 are all other protection categories as included in Santika et al. 2017 (such as Hutan Lindung (Kalimantan) and permanent forest reserves, virgin jungle reserves and wildlife reserves (Sabah) 


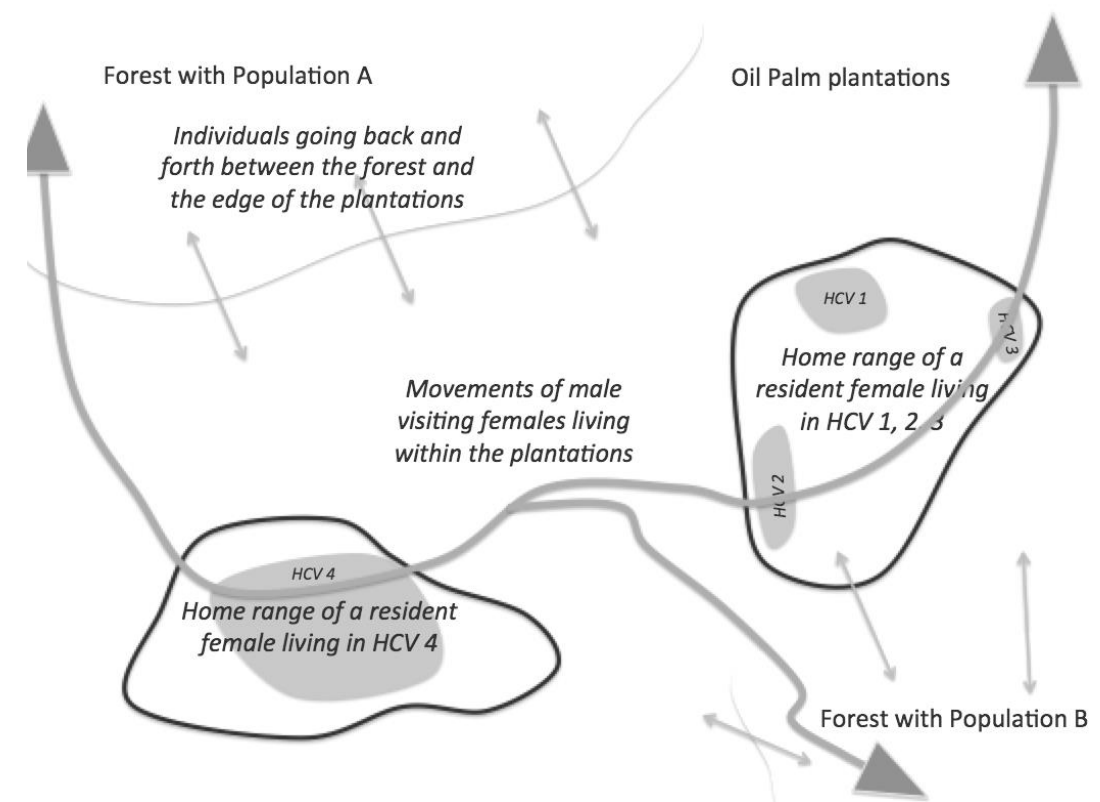

Figure 7. Movement patterns of orangutans in mosaic landscapes. Data from HUTAN-Kinabatangan Orang-utan Conservation Program

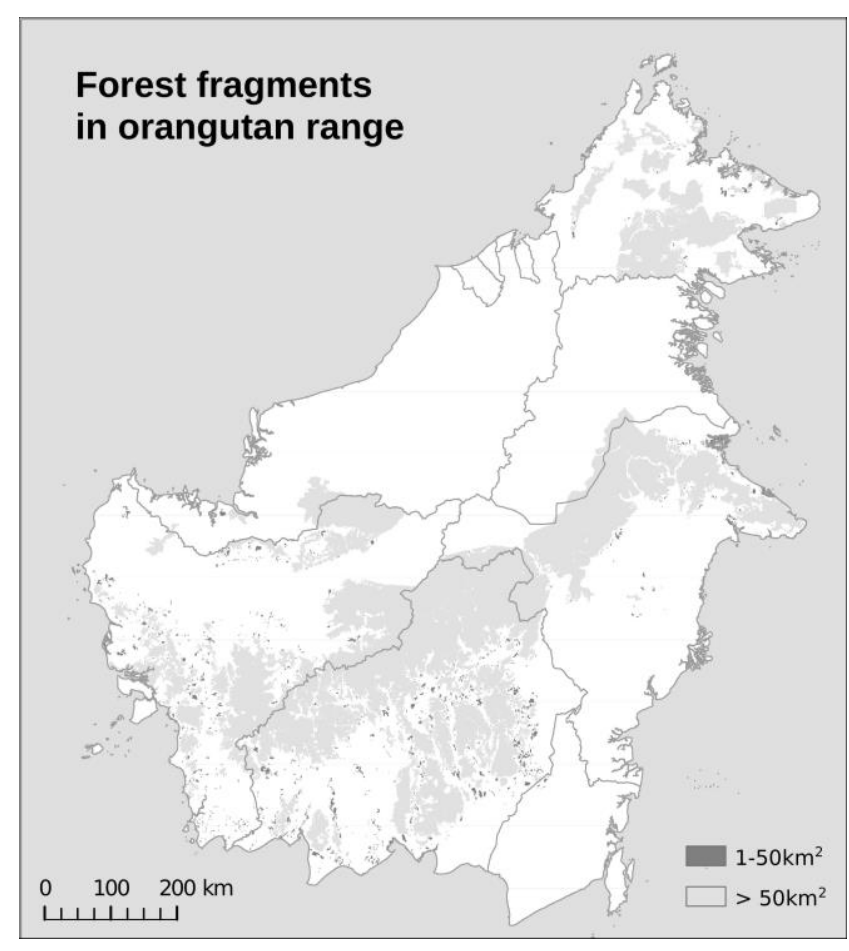

Figure 8. Orangutans in forest fragments. These fragments are essential links between the major orangutan populations in larger habitat areas (larger orangutan habitat areas are shown in light grey). This map does not show fragments that are less than $1 \mathrm{~km}^{2}$, but these tiny fragments are also vital to sustain connectivity between isolated forests. There may be tens of thousands of such tiny fragments

\section{Discussion}

Research findings indicate orangutans can survive in disturbed and human-dominated landscapes, meaning a key management focus should be to minimize the killings that often occur in landscapes where people and orangutans frequently meet. In the absence of killing, orangutans survive in highly fragmented forest areas embedded in industrial agriculture dominated landscapes. The large majority of orangutans on Borneo occur in areas where they frequently encounter people, and thus conservation solutions must effectively incorporate these people.

\section{The role of rescue, rehabilitation, and reintroduction}

Rescue of animals seized during law enforcement action, and provision of improved welfare for these animals, is an important role of rescue centers (Sherman and Greer 2018). Rehabilitation and reintroduction can likewise provide an opportunity to re-establish locally extirpated populations and reinforce populations below carrying capacity (Beck et al. 2007; IUCN/SSC 2013). In the case of Bornean orangutans, possibilities for wellmanaged releases that comply with IUCN reintroduction guidelines are constrained by the sheer number of orangutans in captive care, coupled with the limited available habitats with absent or sufficiently low resident wild orangutan populations that can be adequate protected from poaching and land clearing (CITES/GRASP 2006; Russon 2009). Together with the apparent feedback cycle that encourages turnover of pet orangutans to rescue facilities without a connection to increased deterrence of illegal orangutan harm, killing, and possession (Nijman 2017; Karokaro and Hanafiah 2019), this underscores that rescue and reintroduction should not be seen as the primary intervention to secure long-term viability of $P$. pygmaeus. At best, it should be viewed as a tool to provide a chance for a relatively small number of psychologically, behaviorally and physically suitable individuals to be readapted to semi-wild or wild conditions of life. 


\section{Wild capture and translocation of orangutans}

Wild-to-wild translocations are seen as a solution for orangutans living outside protected areas in Indonesia. In Kalimantan, translocations have been removing and translocating entire viable populations from agricultural mosaic landscapes they could likely have thrived in if properly managed. The single available estimate suggests the majority of the translocated animals have disappeared and may not have survived after a few years, which means these populations could be simply lost, and that individual welfare of released animals is not ultimately improved. While there are isolated cases where capture and translocation is warranted, the practice of moving orangutans to prevent potential conflict appears to be creating the expectation that people need not accept living near these animals and that moving them out of the way is a positive outcome for orangutan conservation and people (ProKal 2017). A new paradigm is needed to prevent removal of wild orangutans except in the most extreme circumstances. The number of orangutans outside protected areas may number in the tens of thousands in Kalimantan alone (Utami-Atmoko et al. 2017). Removing this number is beyond the capacity of rescue programs, and suitable release sites do not exist to accommodate such numbers. It is therefore important to refocus efforts on protecting orangutans in forest patches outside the State Forest land (Indonesia) and protected lands in both Indonesia and Malaysia. This will require additional efforts on law enforcement and effective conflict mitigation, and increased buy-in from the government authorities to address in situ solutions.

\section{Enforcement of orangutan protection laws}

The vast majority of illegal actions against orangutans in range countries likely go unremarked by authorities. The apparent modus operandi of both the government and rescue centers of focusing on rescue without accompanying investigation and prosecution of law-breaking has been identified by the Convention on International Trade in Endangered Species of Wild Fauna and Flora (CITES) and wildlife crime researchers as a systemic failure (CITES/GRASP 2006; Nijman 2017). Orangutan killing rates continue to be high, as most of the animals coming into rescue centers are in some way associated with killing (i.e. dependent infants recovered without their mothers) or outright injury (gunshot or knife wounds) to orangutans. It is obvious from newspaper reports and rescues that significant numbers of orangutans are being lost in this manner and that this is a threat that needs to be taken more seriously. Overall, conviction and prosecution of people keeping, harming or killing orangutans are extremely low, and insufficient to provide deterrence. Nijman (2017) and Freund et al. (2017) provide detailed recommendations to improve law enforcement. We encourage the prompt adoption of these suggestions which are predicated on increased willingness to pursue enforcement action for illegal activities. Nijman (2017) recommends investigation and prosecution of every instance of orangutan trade (trade encompasses buying, selling trading or keeping orangutans). We additionally encourage rational sentencing guidelines that take into account the prevalence of orangutan trade by both local villagers and large corporate concessions. Freund and others (2017) recommend higher fines and prison time for concessions that illegally clear lands outside their boundaries. Nijman (2017) and Sherman and Greer (2018) recommend rescue centers' agreement to take in illegally held animals on behalf of the government should be explicitly tied to government agreement to investigate and prosecute offenders. Prosecutions should be widely publicized to encourage deterrence (Nijman 2017; Sherman and Greer 2018). We also recommend studies be conducted to test messages, tools, and training that would foster human-orangutan conflict mitigation and mutual tolerance, including compensation for crop-raiding and other orangutan related losses. Ongoing studies on the anthropology of orangutan killing will be helpful to inform the kind of messages that could result in lasting perception and behavior change.

Moving orangutans from their habitat are also forbidden under Indonesian law UU 5 of 1990 unless this is needed to save the species or if the animal is a threat and could harm people. Nonetheless, capture and removal of orangutans from industrial agriculture and forestry concessions is commonplace despite its undermining the intactness and functions of orangutan metapopulations and thereby the species' conservation. Although the need for BMPs for rare species on industrial plantations is fairly well understood and accepted at senior and mid-management level, the uptake and their field implementation are relatively limited. Indeed, these BMPs need to be translated into practical "Standard Operation Procedures" (SOPs) that in turn must be incorporated into actual on-the-ground management. This is challenging for most companies because they lack the capacity to understand, interpret and implement these kinds of BMPs and associated SOPs. Most of the time, companies will rely on outside consultants or NGOs to deal with an "orangutan issue," missing an opportunity to become actively engaged in orangutan management themselves. A necessary first step for companies would be to institutionalize orangutan management through developing their own in-house capacity to identify, monitor, and manage biodiversity elements that occur within their estates. Companies should employ their own teams of ecologists to monitor and manage all $\mathrm{HCV}$ forests in their plantations. These teams need to have sufficient authority to influence estate planning that would be more in line with company commitments towards biodiversity conservation. Because the core business of these companies is not biodiversity conservation, developing such an approach may require attaching the services of primatologists and professional orangutan experts to guide management strategies and to train the in-house sustainability teams on orangutan management and monitoring. Developing and implementing management plans for protected species including orangutans is becoming a requirement for certification, indicating that willingly or not, private estates operating in orangutan range will be increasingly be held responsible for managing this species within their boundaries. 
Very little information is available about smallholder interactions with orangutans. Considering the small size of their plots smallholders rarely set aside forest patches in their fields. Orangutans are often perceived as a "pest" by most smallholders, and have been for a long time (De Telegraaf 1934), and the majority of the people prefer to not see an orangutan within their fields. Despite full legal protection of orangutans, people who encounter orangutans on their land will either try to drive the orangutan away from their fields; ask a governmental or non-governmental organization to translocate the problem animals; or sometimes kill the animal (Davis et al. 2013; Abram et al. 2015). Considering that smallholders represent about $40 \%$ of the total surface area planted with oil palms across Borneo (Naylor et al. 2019), and acknowledging that several thousands of orangutans are found within oil palm landscapes, it becomes urgent to reach out to smallholders to shift their mindset and increase their tolerance toward orangutans. In particular, there is a need to work with them to identify peaceful mitigation options in case of conflicts (including compensation); and to design better connectivity in the landscape by considering an entire jurisdiction. Payments to communities who effectively protect local orangutan habitat and populations could also be considered.

\section{Orangutans in forest fragments}

Translocating orangutan from small forest patches in agricultural landscapes is an increasingly common tool in orangutan conservation. The arguments are that the forest patches are doomed anyway to be converted to non-forest, and that the orangutans would otherwise be killed. Our analysis of translocation outcomes and recent scientific studies on orangutan habitat use indicate that removing orangutans from forest patches that are still connected by vegetation types used by orangutans for dispersal (including mature oil palm and acacia plantations), undermines the metapopulation structure (Ancrenaz et al. 2015; Spehar and Rayadin 2017; Oram 2018; Oram et al. 2019). One other problem with the argument for removal and translocation is that once the orangutans are removed from a forest patch (or at least those animals that could be captured), the forest patch and its other remaining wildlife are more likely to be lost, because the forest patch has lost what little protection it received because it contained orangutans. The loss of the forest patch thus means the loss of all other wildlife that was not rescued as well as loss of ecosystem services provided by the forest. Riparian forests in Indonesia and Malaysia need to be maintained by law and to comply with oil palm certification standards (Sabah Water Resources Enactment 1998; Republic of Indonesia 2011; Barclay et al. 2018) but are nonetheless often converted to non-forest. These riparian forests provide habitats for a range of species, and maintain water quality and freshwater diversity, thus providing services to local communities (Abram et al. 2014; Mitchell et al. 2018; Sudrajat and Putro 2019). Similarly, forest patches in agricultural landscapes provide habitat for a range of mammals, including orangutans, birds, and insects that use these as stepping stones in transient landscapes (Lammertink 2004; Bernard et al. 2014; Lucey et al. 2014;
Sudrajat and Putro 2019). Furthermore, forest patches and linear fragments play important roles in preventing floods (Wells et al. 2016).

A better decision-making tool is needed to determine the best option between the two strategies of "rescuing" orangutans from isolated forest patches or investing in retaining these patches with their orangutans and other wildlife, and ecosystem services. While the rescue of orangutans entails a short term cost and effort compared with the long term cost and management effort of maintaining forest patches, these patches enable survival not only of resident orangutans but other wildlife, as well as securing water quality, flood prevention, and associated human wellbeing benefits. In some rare circumstances orangutans may be in immediate danger from humans or fires, need medical care, or be isolated in an area where access to other forest habitat is entirely blocked or too distant, in which cases rescue and translocation may be an alternate solution. In general, however, orangutans are able to travel on the ground or through non-forest habitats to access food resources and other socioecological needs in other forest patches (Ancrenaz et al. 2014; Spehar et al. 2018). Further, interviewees for this study report that evidence is lacking on whether orangutans are likely to survive their removal to another habitat where they do not have established social relationships with other residents nor knowledge of where to find food resources (Kaye 2016; Oram et al. 2019). Currently, given the hundreds of orangutans rescues annually, the choice to rescue is taken relatively easily, but there is insufficient consideration of the impacts this has on the overall orangutan metapopulation, other wildlife, and ecosystem services that are likely lost once orangutans are rescued. Multiple stakeholders reported to us what rescue data and some news stories data collected for this study also suggest: That rescue and translocation create a framework in development and conservation thinking in which orangutans that are in the way of development or are inhabiting forest fragments can simply be "rescued" and moved elsewhere as a "win-win" for conservation and development, without consideration of the costs to overall conservation objectives and environmental health (Asrianti 2011; Kaye 2016; ProKal 2017).

Clear-cutting forest patches make the overall landscape less and less suitable for orangutans and other wildlife. Where hunting is not an issue, orangutans can use an extensive oil-palm or forestry plantation landscape, but to do so they need forest corridors and forest patches (Ancrenaz et al. 2014; Ancrenaz et al. 2015; Spehar and Rayadin 2017). If these small islands of forests are removed, the animals cannot use the landscape anymore and the population becomes extremely fragmented and not viable in the long-term. The long-term option would be to design landscapes that incorporate existing plantations, which could also accommodate orangutans. The goal for these mosaic landscapes should be saving natural habitat (whatever size the patches) that can help support orangutan populations, versus removal of individual animals at the cost of losing habitat for local wild orangutans. A paradigm shift is needed about how people view what is a proper 
orangutan habitat: Along with critically important protected forests, well designed agricultural landscapes could play a role in helping to sustain the species.

\section{A future for the Bornean orangutan}

Effective conservation of Bornean orangutans is both necessary and feasible given the species' flexibility in habitat use, but will require refocused and renewed efforts by stakeholders. Key recommendations for improved orangutan populations outcomes are: (1) Forest fragments in orangutan habitat range should be protected and connected; (2) Law enforcement in Indonesia must be improved and strategies must be developed to help manage and mitigate human-orangutan conflict without removal of animals in multiple-use landscapes; (3) Rescue, rehabilitation and reintroduction or reinforcement of existing wild populations should not be considered the primary means to ensure population viability; and (4) Wildto-wild translocation is not an appropriate conservation strategy for orangutans. We are continuing our studies to determine the most cost-effective strategies for maintaining current wild orangutan populations or increasing them to a new stable and viable population size.

\section{ACKNOWLEDGEMENTS}

We would like to thank the United States Fish and Wildlife Service International Program Great Ape Conservation Fund and the IUCN SSC Primate Specialist Group Section on Great Apes (SGA) for supporting evaluation of Bornean orangutan conservation strategies. We also thank the reviewer for valuable comments. The authors declare no competing interests.

\section{REFERENCES}

Abram NK, Meijaard E, Ancrenaz M, Runting RK, Wells JA, Gaveau DLA, Pellier A-S, Mengersen K. 2014. Spatially explicit perceptions of ecosystem services and land cover change in forested regions of Borneo. Ecosyst Serv 7: 116-127.

Ancrenaz M, Gumal M, Marshall AJ, Meijaard E, Wich SA, Husson S. 2016. Pongo pygmaeus. The IUCN Red List of Threatened Species 2016: e.T17975A17966347.

Ancrenaz M, Oram F, Ambu L, Lackman I, Ahmad E, Elahan H, Meijaard E. 2015. Of pongo, palms, and perceptions-A multidisciplinary assessment of orangutans in an oil palm context. Oryx 49: 465-472.

Ancrenaz M, Sollmann R, Meijaard E, et al. 2014. Coming down the trees: Is terrestrial activity in orangutans natural or disturbancedriven? Sci Rep 4: 4024. DOI: 10.1038/srep04024.

Asrianti T. 2011. No justice for C. Kalimantan orangutans. Jakarta Post. https: //www.thejakartapost.com/news/2011/12/09/no-justice-ckalimantan-orangutans1.html.

Barclay H, Gray C, Luke S, Nainar A, Snaddon J, Turner E. 2018. RSPO Manual on Best Management Practices (BMPs) for the management and rehabilitation of riparian reserves. https: //www.rspo.org/resources/conservation-sustainable-management-ofnatural-resources/best-management-practices-for-riparian-areas.

Beck BB, Walkup K, Rodriques M, Unwin S, Travis D, Stoinski T 2007. Best practices guidelines for the re-introduction of great apes. SSC Primate Specialist Group of the World Conservation Union, Gland, Switzerland.

Bernard H, Baking EL, Giordano AJ, Wearn OR, Ahmad AH. 2014 Terrestrial mammal species richness and composition in three small forest patches within an oil palm landscape in Sabah, Malaysian Borneo. Mammal Stud 39: 141-154.

CITES/GRASP. 2006. CITES/GRASP Orang-utan Technical Mission Indonesia. Geneva, Switzerland.

Davis JT, Mengersen K, Abram N, Ancrenaz M, Wells J, Meijaard E. 2013. It's not just conflict that motivates killing of orangutans. PLoS ONE 8: e75373. DOI: 10.1371/journal.pone.0075373.

De Telegraaf. 1934. Kolonië. Palmoliecultuur Nederl. Indië. De Telegraaf-Avondblad. //www.delpher.nl/nl/kranten/view?query=orangoetan+AND+dood $\&$ coll $=$ ddd $\&$ identifier $=$ ddd $\% 3 \mathrm{~A} 110572386 \% 3 \mathrm{Am}$ peg $21 \% 3 \mathrm{Aa} 0310 \&$ resultsidentifier $=\mathrm{ddd} \% 3 \mathrm{~A} 110572386 \% 3 \mathrm{Ampeg} 21$ $\% 3 \mathrm{Aa} 0310$. [Dutch]

ESRI. 2014. ArcGIS Desktop: Release 10. Redlands, CA, USA.

Foresthints. 2019. Action plan for orangutans revoked for upgrade. https: //www.foresthints.news/action-plan-for-orangutans-revoked-forupgrade.

Freund C, Rahman E, Knott C. 2017. Ten years of orangutan-related wildlife crime investigation in West Kalimantan, Indonesia. Am J Primatol 79.

FSC. 2009. FSC step-by-step guide. http: //ic.fsc.org/file-download.fscstep-by-step-pocket-guide.16.htm.

GADM. 2012. Global Administrative Areas database. https: //gadm.org/

Gaveau DLA, Kshatriya M, Sheil D, et al. 2013. Reconciling forest conservation and logging in Indonesian Borneo. PLoS ONE 8: e69887.DOI: 10.1371/journal.pone.0069887.

Gaveau DLA, Salim M, Arjasakusuma S. 2016. Deforestation and industrial plantations development in Borneo. Center for International Forestry Research (CIFOR), Bogor.

Goossens B, Chikhi L, Ancrenaz M, Lackman-Ancrenaz I, Andau P, Bruford MW. 2006. Genetic signature of anthropogenic population collapse in orang-utans-art. no. e25. PLoS Biol 4: 285-291.

Gumal M, Braken Tisen O. 2010. Orangutan Strategic Action Plan: TransBoundary Biodiversity Conservation Area. Kuching, Malaysia

Husson SJ, et al. 2009. Orangutan distribution, density, abundance and impacts of disturbance. In: Wich SA, Atmoko SU, Setia TM, van Schaik CP (eds) Orangutans: Geographic Variation in Behavioral Ecology and Conservation. Oxford University Press, Oxford, UK.

IUCN/SSC. 2013. Guidelines for Reintroductions and Other Conservation Translocations. Version 1.0. World Conservation Union, Cambridge, UK \& Gland, Switzerland.

Karokaro AS, Hanafiah J. 2019. Indonesia rescues captive orangutans, but leaves their owners untouched. Mongabay. https: //news.mongabay.com/2019/02/indonesia-rescues-captiveorangutans-but-leaves-their-owners-untouched/.

Kaye M. 2016. Orangutan refugees: weighing when to rescue the apes. Mongabay. https: //news.mongabay.com/2016/03/orangutan-refugeesweighing-when-to-rescue-the-apes/.

KSDAE. 2018. Laporan Kinerja 2018. Jakarta, Indonesia. [Indonesian]

Lammertink M. 2004. A multiple-site comparison of woodpecker communities in Bornean lowland and hill forests. Conserv Biol 18: 746-757.

Lucey JM, Tawatao N, Senior MJM, Chey VK, Benedick S, Hamer KC, Woodcock P, Newton RJ, Bottrell SH, Hill JK. 2014. Tropical forest fragments contribute to species richness in adjacent oil palm plantations. Biol Conserv 169: 268-276.

Meijaard E, Buchori D, Hadiprakarsa Y, et al. 2011. Quantifying killing of orangutans and human-orangutan conflict in Kalimantan, Indonesia. PLoS ONE 6: e27491. DOI: 10.1371/journal.pone.0027491

Meijaard E, Morgans C, Husnayaen, Abram NK, Ancrenaz M. 2017. An Impact Analysis of RSPO Certification on Borneo Forest Cover and Orangutan Populations Borneo Futures, Bandar Seri Begawan, Brunei Darussalam.

Meijaard E, Sherman J, Ancrenaz M, Wich SA, Santika T, Voigt M. 2018. Orangutan populations are certainly not increasing in the wild. Curr Biol 28: R1241-R1242.

Meijaard E, Welsh A, Ancrenaz M, Wich S, Nijman V, Marshall AJ. 2010. Declining orangutan encounter rates from Wallace to the present suggest the species was once more abundant. PLoS ONE 5: e12042.

Ministry of Forestry. 2009. Orangutan Indonesia Conservation Strategies and Action Plan 2007-2017. Jakarta, Indonesia.

Mitchell SL, Edwards DP, Bernard H, Coomes D, Jucker T, Davies ZG, Struebig MJ. 2018. Riparian reserves help protect forest bird communities in oil palm dominated landscapes. J Appl Ecol 55: 27442755 . 
MOEF. 2018. 2018. The State of Indonesia's Forests 2018. Ministry of Environment and Forestry, Republic of Indonesia.

Naylor RL, Higgins MM, Edwards RB, Falcon WP. 2019. Decentralization and the environment: Assessing smallholder oil palm development in Indonesia. Ambio 48: 1195-1208.

Nijman V. 2017. Orangutan trade, confiscations, and lack of prosecutions in Indonesia. Am J Primatol 79.

Oliphant T. 2015. Guide to NumPy. 2nd ed. CreateSpace Independent Publishing Platform, Santa Monica.

Oram F. 2018. Abundance, feeding and behavioural ecology of orangutans (Pongo pygmaeus morio) in the fragmented forests of the Kinabatangan floodplain. Page 350. University Malaysia Sabah (ITBC), Kota Kinabalu, Sabah.

Oram F, Elahan H, Daisah Kapar M, Maharan W, Bernard H, Lackman I, Ancrenaz M, Payne J. 2019. Conservation Across Boundaries-Coexistence of Wild Orang-utans and Oil Palm. 8th European Federation of Primatology Meeting \& Primate Society of Great Britain winter meeting 2019, Oxford, United Kingdom.

Pandong J, Gumal M, Aton ZM, Sabki MS, Koh LP. 2019. Threats and lessons learned from past orangutan conservation strategies in Sarawak, Malaysia. Biol Conserv 234: 56-63.

ProKal. 2017. Orangutan yang Masuki Kebun Warga Kembali Dilepasliarkan ProKalteng. http: //kalteng.prokal.co/read/news/41643orangutan-yang-masuki-kebun-warga-kembali-dilepasliarkan.html. [Indonesian]

R Core Development Team. 2016. R: A language and environment for statistical computing. R Foundation for Statistical Computing. http: //www.R-project.org/. Vienna, Austria.

Republic of Indonesia. 2011. Peraturan Pemerintah Republik Indonesia Nomor 38 Tahun 2011 tentang Sungai (pp. Pasal 10, Ayat 11). Government of the Republic of Indonesia, Jakarta, Indonesia. [Indonesian]

RSPO. 2018. Principles and criteria for the production of sustainable palm oil 2018. http: //www.cmzoo.org/docs/RSPO-PC11-15-2018 Principles-Criteria.pdf.

Russon AE. 2009. Orangutan rehabilitation and reintroduction. In: Wich S, Atmoko SU, Setia TM, van Schaik CP (eds.). Orangutans: Geographic Variation in Behavioral Ecology and Conservation. Oxford University Press, Oxford, UK.

Sabah Water Resources Enactment. 1998. Sabah Water Resources Enactment in Sabah, Malaysia.
Sabah Wildlife Department. 2012. Sabah Wildlife Department Orang-utan Action Plan 2012-2016. Kota Kinabalu, Sabah, Malaysia.

Santika T, Ancrenaz M, Wilson KA, et al. 2017. First integrative trend analysis for a great ape species in Borneo. Sci Rep 7: 4839. doi: 10.1038/s41598-017-04435-9.

Santika T, Meijaard E, Wilson KA. 2015. Designing multifunctional landscapes for forest conservation. Environ Res Lett 10: 114012. DOI: $10.1088 / 1748-9326 / 10 / 11 / 114012$

Sherman J, Greer D. 2018. The status of captive apes: beyond capacity: sanctuaries and the status of captive apes in shrinking natural habitats. In: Arcus Foundation (ed) State of the Apes: Infrastructure Development and Ape Conservation. Cambridge University Press, Cambridge, UK.

Simon D, Davies G, Ancrenaz M. 2019. Changes to Sabah's orangutan population in recent times: 2002-2017. PLoS ONE 14: e0218819. DOI: 10.1371/journal.pone.0218819.

Spehar SN, Rayadin Y. 2017. Habitat use of Bornean orangutans (Pongo pygmaeus morio) in an industrial forestry plantation in East Kalimantan, Indonesia. Int J Primatol 1-27.

Spehar SN, Sheil D, Harrison T, Louys J, Ancrenaz M, Marshall AJ, Wich SA, Bruford MW, Meijaard E. 2018. Orangutans venture out of the rainforest and into the Anthropocene. Sci Adv 4: e1701422. DOI: 10.1126/sciadv. 1701422 .

Sudrajat, Putro M. 2019. The contribution of forest remnants within industrial area to threatened mammal conservation: A case study in liquefied natural gas industry in Bontang, Indonesia. Biodiversitas 20: 2257-2265.

Utami-Atmoko et al. 2017. Orangutan Population and Habitat Viability Assessment: Final Report (draft version). Apple Valley, MN.

Voigt M, et al. 2018. Global demand for natural resources eliminated more than 100,000 Bornean orangutans. Curr Biol 28: 761-769.

Wells JA, Wilson KA, Abram NK, Nunn M, Gaveau DLA, Runting RK, Tarniati N, Mengersen KL, Meijaard E. 2016. Rising floodwaters: mapping impacts and perceptions of flooding in Borneo. Environ Res Lett 11: 064016.

Wich SA, Gaveau D, Abram N, et al. 2012. Understanding the Impacts of land-use policies on a threatened species: Is there a future for the Bornean orang-utan? PLoS ONE 7: e49142. DOI: 10.1371/journal.pone.0049142

Wich SA, Meijaard E, Marshall AJ, et al. 2008. Distribution and conservation status of the orang-utan (Pongo spp.) on Borneo and Sumatra: how many remain? Oryx 42: 329-339. 